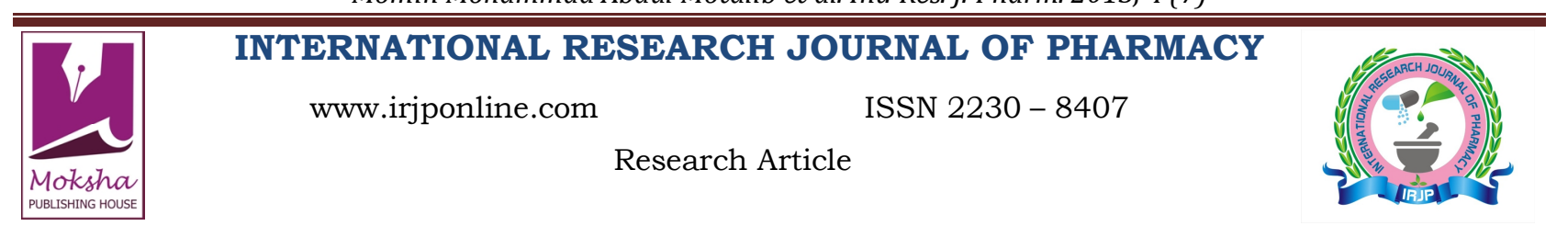

\title{
DEVELOPMENT AND VALIDATION OF METHOD FOR DETERMINATION OF CICLESONIDE INN (MICRONIZED) BY HPLC
}

Momin Mohammad Abdul Motalib ${ }^{1}$, Anisuzzaman Sharif Md. ${ }^{1}$, Begum Anjuman Ara ${ }^{1}$, Bellah Sm Faysal ${ }^{2}$, Islam Md. Mostaharul ${ }^{3}$, Talukder Parimal ${ }^{4}$

${ }^{1}$ Department of Pharmacy, Jahangirnagar University, Savar, Dhaka, Bangladesh

${ }^{2}$ Department of Clinical Pharmacy and Pharmacology, University of Dhaka, Dhaka, Bangladesh

${ }^{3}$ Department of Pharmacy, Rajshahi University, Rajshahi, Bangladesh

${ }^{4}$ Square Pharmaceuticals Limited, Kaliakoir, Gazipur, Bangladesh

*Corresponding Author Email: anjumantanya@yahoo.com

Article Received on: 20/05/13 Revised on: 18/06/13 Approved for publication: 17/07/13

DOI: $10.7897 / 2230-8407.04712$

IRJP is an official publication of Moksha Publishing House. Website: www.mokshaph.com

(C) All rights reserved.

\section{ABSTRACT}

A simple, selective and rapid reversed phase high performance liquid chromatographic (RPHPLC) method for the analysis of Ciclesonide has been developed and validated. The separation was achieved from HPLC Column (Waters Symmetry C18 $5 \mu$; $4.6 \mathrm{~mm}$ x $250 \mathrm{~mm}$ ) with a mobile phase consisting of 85 volume of Ethanol with 15 volume of Millie-Q-Water at a flow rate of $1.10 \mathrm{ml} / \mathrm{min}$ with UV detection at $242 \mathrm{~nm}$. The method is specific and it is observed that no interference with diluents. The proposed method is accurate with $99.6 \%$ recovery for Ciclesonide and precise (\% RSD of area of system precision, \% RSD of assay of method precision and Intermediate precision are found to be $0.20 \%, 0.20 \%$ and $0.20 \%$ respectively). From the linearity study the correlation coefficient is found to be 0.9999 , which indicates that the method is linear over $10 \%$ to $150 \%$ range. The method is found robust for possible changes. Therefore, this method can be used as a more convenient and efficient option for the analysis of Ciclesonide to establish the quality of the drug substance during routine analysis with consistent and reproducible results.

Keywords: Validation, HPLC, Development, Ciclesonide.

\section{INTRODUCTION}

The Ciclesonide is a non-halogenated glucocorticoid having the chemical name pregna-1, 4-diene-3, 20-dione, 16, 17[[(R)-cyclohexylmethylene] bis (oxy)]-11-hydroxy-21-(2methyl-1-oxopropoxy), $(11 \beta, 16 \alpha)$. The empirical formula is $\mathrm{C}_{32} \mathrm{H}_{44} \mathrm{O}_{7}$ and its molecular weight is 540.7. Ciclesonide is a white to yellow-white powder. It is soluble in dehydrated alcohol, acetone, dichloromethane and chloroform. Ciclesonide is used to treat asthma and allergic rhinitis. The side effects of Ciclesonide include headache, nosebleeds and inflammation of the nose and throat linings. ${ }^{1}$ In the lung, Ciclesonide is metabolized to its active metabolite which has a higher affinity for glucocorticoid receptors. Although Ciclesonide has a different structure, it still acts like other inhaled corticosteroids by reducing bronchial hyper-reactivity and inflammation in the airways. Validation is a fast growing and evolving subject. Validation in a requirement that has always made sense from both a regulatory and quality perspective. ${ }^{2,3}$ As the analytical process varies so widely there is no universal approach to validation regulatory bodies such as FDA and EC for medicinal products have developed general non-mandatory guidelines. ${ }^{4,5}$ The most common reason for validation is to guarantee as for as possible that all processes and machinery in the Pharmaceutical manufacturing process are being used in a way which will ensure safety, integrity, quality and strength of the product for use by the general public., ${ }^{6,7}$ The official methods for determination of Ciclesonide by liquid chromatography include in Indian pharmacopoeia - 2007. ${ }^{8,9}$ other methods available for identification as well as determination of Ciclesonide include LC-MS/MS ${ }^{10}$ and UV-visible spectrophotometry. ${ }^{11}$ But these methods are for the combined preparation and only few methods are available for determination of Ciclesonide in bulk drugs, so the present work was undertaken with the aim to develop and validate a rapid and consistent reversed-phase high performance liquid chromatographic method for determination for Ciclesonide in bulk drug according to ICH guideline. ${ }^{12}$

\section{MATEREALS AND METHODS}

\section{Reagents and Chemicals}

HPLC grade Ethanol from Merck, Germany; Ciclesonide (INN) working standard (WS) from Cipla Ltd. India were used in this study. Purified water was used for the analytical purpose.

\section{Instruments}

A Waters Alliance 2695 separation module with PDA detector, USA was used. The HPLC method used a Water symmetry C18 $5 \mu, 4.6 \mathrm{~mm}$ x $250 \mathrm{~mm}$ column. Analytical Balance, $\mathrm{pH}$ meter from Mettler, UK and Micropipette from Fischer, Germany was used.

\section{Method Development}

\section{Preparation of Mobile Phase}

A mixture of Ethanol and purified water in the ratio of $85: 15$ was prepared and the mixture was filtered through $0.45 \mu$ nylon membrane and then degassed.

\section{Preparation of Diluent \\ HPLC Grade Absolute Ethanol}

\section{Chromatographic Conditions}

Column used in this method: Waters Symmetry C18 $5 \mu ; 4.6$ $\mathrm{mm} \times 250 \mathrm{~mm}$, injection volume was $50 \mu \mathrm{l}$. Detection was carried out at $242 \mathrm{~nm}$ and the flow rate was $1.10 \mathrm{ml} / \mathrm{min}$.

\section{Reference Solution}

$16.0 \mathrm{mg}$ of Ciclesonide working standard was taken in to a $100 \mathrm{ml}$ volumetric flask. Diluent was added and sonicated to 
dissolve. Then $5 \mathrm{ml}$ of this solution was diluted to $50 \mathrm{ml}$ with diluent.

\section{Preparation of Test Solution}

$16.0 \mathrm{mg}$ of the test sample was taken in to a $100 \mathrm{ml}$ volumetric flask. Diluent was added and sonicated to dissolve. Diluent was added to make the volume $100 \mathrm{ml}$ and was mixed well. Then $5 \mathrm{ml}$ of this solution was diluted to 50 ml with diluent.

\section{System Suitability solution}

The Reference solution is used as a system suitability solution and $50 \mu \mathrm{l}$ of five replicate injections of Reference solution were injected. The chromatogram was recorded and the system suitability parameters for each of the injection was checked and also was checked for $\%$ RSD of area within 1.0 $\%$ and Tailing factor not more than 2.0, Plate count not less than 1000 .

\section{Method Validation System Suitability}

The system was deemed suitable if the following acceptance criteria were satisfied. The relative standard deviation $(\%$ RSD) of the peak area responses for Ciclesonide from five replicate injections of Reference solution is not more than 2.0 $\%$, The tailing factor is not more than 2.0 , theoretical plate counts in is not less than 1000 .

\section{Specificity}

For specificity study identification, placebo (diluents) interference and RT ratio of Sample and Standard were observed.

\section{Linearity}

The linearity was carried out by observing the correlation coefficient (r) of standard solution.

\section{System Precision}

System Precision was carried out by performing six replicate Injections of standard at $100 \%$ of the test concentration and calculating the $\%$ RSD of the measured area.

\section{Method Precision}

To demonstrate method precision, six replicate of sample against standard at $100 \%$ of test concentration was carried out and the precision of method was calculated by computing $\%$ RSD of six measurements.

\section{Intermediate Precision (Ruggedness)}

Intermediate precision or Ruggedness study of an analytical method is the degree of reproducibility of the test results obtain by the analysis of the same samples under a variety of normal test conditions. Test sample of Ciclesonide representing single batch was analyzed by two different analysts on two different equipments and on two different days. The ruggedness of the test method was calculated by measuring \% RSD of six results and \% RSD of results of two analysts.

\section{Accuracy}

Study was carried out over a range of $80 \%, 100 \%$ and 120 $\%$ (3 replicates each) of the test concentration. The $\%$ recovery and $\mathrm{RSD}$ of $\%$ recovery for each concentration was also measured.

\section{Range}

Data generated in linearity, precision and accuracy were considered for establishing the range of the analytical method.

\section{Robustness}

Robustness of the method was investigated by changing flow rate $( \pm 0.1 \%)$, changing column temperature $\left( \pm 5^{\circ} \mathrm{C}\right)$, and ratio of components of mobile phase.

\section{Stability Study}

The solution stability experiments were carried out under room temperature at intervals of $0 \mathrm{~h}, 6 \mathrm{~h}, 12 \mathrm{~h}, 18 \mathrm{~h}, 24 \mathrm{~h}, 30$ $\mathrm{h}$ and $48 \mathrm{~h}$.

\section{RESULTS AND DISCUSSION \\ System Suitability}

System suitability is an integral part of analytical procedures. In optimized chromatographic conditions Relative Standard Deviation (\% RSD) of area of Ciclesonide was 0.08 (NMT $1.0 \%$ ), \% RSD of retention time was 0.27 , Average Tailing factor was 1.4 (NMT 2.0) and theoretical plate count was 1433 (NLT 1000) (Table 1).

\section{Specificity}

Specificity of an analytical method is its ability to assess unequivocally the analyte in the presence of components that may be expected to be present. Lack of specificity of an Individual analytical procedure may be compensated by other supporting analytical Procedures. ${ }^{13}$ From the specificity study it is observed that the chromatogram for Ciclesonide Sample with Ciclesonide reference Standard showed positive response and Blank (diluents) had no response. So the method was specific.

\section{Linearity}

The linearity of an analytical method is its ability to elicit test results directly proportional to the concentration of the analyte in samples within given range. ${ }^{14}$ Linearity of the method was evaluated from the correlation coefficient of calibration curves that were constructed from mean peak area of Ciclesonide at different concentrations level $(10 \%, 20 \%$, $30 \%, 50 \%, 80 \%, 90 \%, 100 \%, 120 \%, 130 \%$ and $150 \%$ ). Correlation coefficient was 0.9999 (Table 2) (Figure 1).

\section{System Precision}

System Precision was carried out by performing six replicate Injections at $100 \%$ of the test concentration and calculating the $\%$ RSD of the measured area. Table 3 shows the system precision data. From the data it is observed that the \% Relative Standard Deviation of area was $0.20 \%$ which was well within the acceptance limit of $2.0 \%$.

\section{Method Precision}

The result shows that the \% RSD of six sample assay results was found to be $0.20 \%$ which was within the acceptance limit (Table 4).

\section{Intermediate Precision or Ruggedness}

Assay results by two different analysts at different days have been found very much close to each other and with a difference of only $0.2 \%$ and the $\%$ RSD of two analysts (12 samples) is $0.20 \%$ which was within acceptance criteria. So the method can be considered to be rugged enough (Table 5). 


\section{Accuracy}

The accuracy of an analytical method is the closeness of test results obtained by that method to the true value. The result shows that Average \% Recovery at different Accuracy level is $99.6 \%$ and \% RSD for individual \% recovery meets the acceptance criteria (Table 6).

\section{Range}

The specified range is normally derived from linearity studies and depends on the intended application of the procedure. It is established by confirming that the analytical procedure provides an acceptable degree of linearity, accuracy and precision when applied to samples containing amounts of analyte within the extremes of the specified range of the analytical procedure. Based on the Linearity, precision and accuracy results, the Range of the method was determined as $80 \%$ to $120 \%$ of the target concentration (Table 7).

\section{Robustness}

The robustness of an analytical method is a measure of its capacity to remain unaffected by small but deliberate variation in method parameters and provides an indication of its reliability during normal usage. ${ }^{15}$ Robustness of the method was investigated by changing flow rate $( \pm 0.1)$, changing column temperature $\left( \pm 5^{\circ} \mathrm{C}\right)$, and ratio of components of mobile phase. From the results presented on Table 8 , it is clear that the system suitability criteria meet with the acceptance limit. Hence the method is robust.

\section{Stability Study}

From the stability study data, it was observed that the test sample solution is found to be stable up to $48 \mathrm{~h}$ at ambient condition. (Table 9)

Table 1: System Suitability Study

\begin{tabular}{|c|c|c|c|c|}
\hline Injection & Area & Retention Time & Tailing Factor & Plate Count \\
\hline 1. & 1240021 & 3.75 & 1.4 & 1430 \\
\hline 2. & 1240063 & 3.74 & 1.4 & 1441 \\
\hline 3. & 1240044 & 3.75 & 1.4 & 1445 \\
\hline 4. & 1241711 & 3.74 & 1.4 & 1420 \\
\hline 5. & 1239073 & 3.74 & 1.4 & 1430 \\
\hline Average ( $\mathrm{n}=5)$ & 1240182 & 3.74 & 1.4 & 1433 \\
\hline Standard deviation & 952.21 & 0.01 & \multicolumn{1}{l}{} \\
\cline { 1 - 3 } \% Relative standard deviation & 0.08 & 0.27 & \multicolumn{1}{l}{} \\
\hline
\end{tabular}

Table 2: Linearity Study

\begin{tabular}{|c|c|c|}
\hline Level & Concentration in \% ( X -axis ) & Area ( Y - axis ) \\
\hline 1. & 10 & 128821 \\
\hline 2. & 20 & 260444 \\
\hline 3. & 30 & 381825 \\
\hline 4. & 50 & 640525 \\
\hline 5. & 80 & 1013319 \\
\hline 6. & 90 & 1143045 \\
\hline 7. & 100 & 1245226 \\
\hline 8. & 120 & 1532850 \\
\hline 9. & 130 & 1658616 \\
\hline 10. & 150 & 1916998 \\
\hline \multicolumn{2}{|c|}{ Correlation coefficient (r) } & 0.9999 \\
\hline \multicolumn{2}{|c|}{ Acceptance Criteria : Correlation coefficient, $\mathbf{r}=\mathbf{0 . 9 9 9 0}$} \\
\hline
\end{tabular}

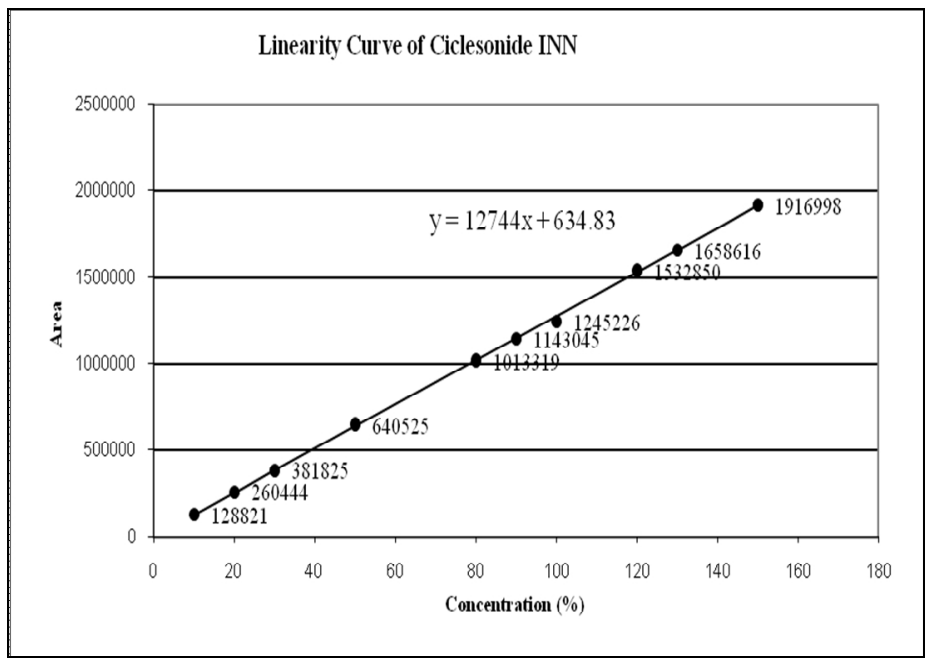

\begin{tabular}{|l|l|}
\hline $\begin{array}{l}\text { Correlation } \\
\text { Coefficient, } \mathrm{R}\end{array}$ & $\mathbf{0 . 9 9 9 9}$ \\
\hline
\end{tabular}

Figure 1: Graphical Representation of Linearity 
Momin Mohammad Abdul Motalib et al. Int. Res. J. Pharm. 2013, 4 (7)

Table 3: System Precision Study

\begin{tabular}{|c|c|c|c|c|}
\hline Sr. No. & Weight of Sample (mg) & Area & Weight of Standard (mg) & Area of Standard \\
\hline 01 & \multirow{6}{*}{15.9} & 1236924 & \multirow{6}{*}{16.13} & \multirow[t]{6}{*}{1240621} \\
\hline 02 & & 1240619 & & \\
\hline 03 & & 1237180 & & \\
\hline 04 & & 1234788 & & \\
\hline 05 & & 1239419 & & \\
\hline 06 & & 1234564 & & \\
\hline \multicolumn{2}{|r|}{ Average $n=6$} & 1237249 & & \\
\hline \multicolumn{2}{|c|}{ Standard deviation } & 2426.60 & & \\
\hline \multicolumn{2}{|c|}{$\%$ Relative Standard deviation (\% RSD) } & 0.20 & & \\
\hline
\end{tabular}

Table 4: Method Precision

\begin{tabular}{|c|c|c|c|c|c|}
\hline Sr. No. & Weight of Sample (mg) & Area & Weight of Standard (mg) & Area of Standard & \% of Assay \\
\hline 01 & 16.0 & 1241676 & \multirow{6}{*}{16.13} & \multirow[t]{6}{*}{1240621} & 99.5 \\
\hline 02 & 16.0 & 1239519 & & & 99.3 \\
\hline 03 & 16.0 & 1241798 & & & 99.5 \\
\hline 04 & 16.0 & 1239373 & & & 99.3 \\
\hline 05 & 15.9 & 1237813 & & & 99.8 \\
\hline 06 & 16.0 & 1239454 & & & 99.3 \\
\hline \multicolumn{5}{|c|}{ Average $n=6$} & 99.5 \\
\hline \multicolumn{5}{|c|}{ Standard deviation } & 0.20 \\
\hline \multicolumn{5}{|c|}{ \% Relative Standard deviation (\% RSD) } & 0.20 \\
\hline
\end{tabular}

Table 5: Table for Intermediate Precision or Ruggedness Study

\begin{tabular}{|c|c|c|c|c|c|c|}
\hline Analyst Name & \multicolumn{3}{|c|}{ Analyst 1} & \multicolumn{3}{|c|}{ Analyst 2} \\
\hline Area of Std. & \multicolumn{3}{|c|}{1240621} & \multicolumn{3}{|c|}{1237999} \\
\hline Sr.No. & Weight of sample (mg) & Area & Assay (\%) & Weight of sample (mg) & Area & Assay (\%) \\
\hline 1. & 16.0 & 1241676 & 99.5 & 16.0 & 1239646 & 99.2 \\
\hline 2. & 16.0 & 1239519 & 99.3 & 16.0 & 1241997 & 99.4 \\
\hline 3. & 16.0 & 1241798 & 99.5 & 16.0 & 1236375 & 99.0 \\
\hline 4. & 16.0 & 1239373 & 99.3 & 15.9 & 1235437 & 99.5 \\
\hline 5. & 15.9 & 1237813 & 99.8 & 16.0 & 1240284 & 99.3 \\
\hline \multirow[t]{4}{*}{6.} & 16.0 & 1239454 & 99.3 & 16.0 & 1237772 & 99.1 \\
\hline & \multicolumn{2}{|c|}{ Mean Assay $n=6$} & 99.5 & \multicolumn{2}{|c|}{ Mean Assay $n=6$} & 99.3 \\
\hline & \multicolumn{2}{|c|}{ Standard deviation $n=6$} & 0.20 & \multicolumn{2}{|c|}{ Standard deviation $\mathrm{n}=6$} & 0.19 \\
\hline & \multicolumn{2}{|c|}{$\%$ Relative standard deviation $\mathrm{n}=6$} & 0.20 & \multicolumn{2}{|c|}{$\%$ Relative standard deviation $\mathrm{n}=6$} & 0.19 \\
\hline
\end{tabular}

Table 6: Accuracy Study

\begin{tabular}{|c|c|c|c|}
\hline Wt of Std.(mg) & Level & Weight of sample (mg) & Amount recovered (\%) \\
\hline \multirow[t]{9}{*}{16.13} & \multirow[t]{3}{*}{$80 \%$} & 12.9 & 99.5 \\
\hline & & 12.8 & 99.8 \\
\hline & & 12.8 & 99.8 \\
\hline & \multirow[t]{3}{*}{$100 \%$} & 16.0 & 99.5 \\
\hline & & 16.1 & 99.2 \\
\hline & & 16.0 & 99.4 \\
\hline & \multirow[t]{3}{*}{$120 \%$} & 19.0 & 99.7 \\
\hline & & 18.9 & 100.2 \\
\hline & & 19.0 & 99.7 \\
\hline \multicolumn{3}{|c|}{ Average $(n=9)$} & 99.6 \\
\hline \multicolumn{3}{|c|}{ Standard Deviation (SD) } & 0.29 \\
\hline \multicolumn{3}{|c|}{ \% Relative Standard Deviation (\% RSD) } & 0.29 \\
\hline
\end{tabular}

Table 7: Range Study

\begin{tabular}{|c|c|c|c|}
\hline Parameter & Concentration Range & Acceptance limit & Result \\
\hline Linearity & $10 \%$ to $150 \%$ & R NLT 0.9990 & $\mathrm{R}=0.9999$ \\
\hline Method Precision & $100 \%$ & $\%$ RSD of Assay NMT $2.0 \%$ & $0.20 \%$ \\
\hline $\begin{array}{c}\text { Intermediate } \\
\text { Precision }\end{array}$ & $100 \%$ & $\begin{array}{c}\% \text { RSD of two analyst NMT } 2.0 \\
\pm 2 \% \text { Difference of each other }\end{array}$ & $\begin{array}{c}\% \text { RSD of } 2 \text { analyst }=0.20 \% \\
\text { Difference of assay }=0.2 \%\end{array}$ \\
\hline Accuracy & $80 \%$ to $120 \%$ & $\begin{array}{c}\% \text { Recovery: }(98-102) \% \text { and } \% \text { RSD: } \\
\text { NMT } 1.0 \%\end{array}$ & $\begin{array}{c}\% \text { Recovy: } 99.6 \%, \\
\text { NMT } 0.29 \%\end{array}$ \\
\hline
\end{tabular}

Table 8: Data of System Suitability (Robustness Study)

\begin{tabular}{|c|c|c|c|}
\hline Parameter & \% RSD of Area & Theoretical Plate Number & Tailing Factor \\
\hline Flow rate $+0.1 \%$ & $0.08 \%$ & 1433 & 1.4 \\
\hline Flow rate $-0.1 \%$ & $0.09 \%$ & 1512 & 1.4 \\
\hline Column Temperature at $40^{\circ} \mathrm{C}$ & $0.08 \%$ & 1442 & 1.4 \\
\hline Column Temperature at $50^{\circ} \mathrm{C}$ & $0.07 \%$ & 1447 & 1.4 \\
\hline Ethanol : Milli-Q-Water $(90: 10)$ & $0.09 \%$ & 1478 & 1.4 \\
\hline Ethanol : Milli-Q-Water $(80: 20)$ & $0.11 \%$ & 1432 & 1.4 \\
\hline
\end{tabular}


Table 9: Solution Stability Study

\begin{tabular}{|c|c|c|}
\hline Measurements & \% of Assay & \% Difference from Initial \\
\hline At $0 \mathrm{~h}$ & 99.6 & - \\
\hline After 6 h & 99.3 & -0.3 \\
\hline After $12 \mathrm{~h}$ & 99.3 & -0.3 \\
\hline After 24 h & 99.1 & -0.5 \\
\hline After 36 h & 99.2 & -0.4 \\
\hline After 48 h & 99.4 & -0.2 \\
\hline
\end{tabular}

\section{CONCLUSION}

The method adopted for estimation of Ciclesonide by HPLC is precise, linear, accurate, rugged and robust enough. The sample solution is found to be stable up to $48 \mathrm{~h}$ at ambient condition. Hence this method can be considered validated for its intended purpose to establish the quality of the drug substance during routine analysis with consistent and reproducible results.

\section{REFERENCES}

1. Mutch E, Nave R, Mc Cracken N, Zech K, Williams FM. The role of esterases in the metabolism of ciclesonide to desisobutyryl-ciclesonide in human tissue. Biochem Pharmacol. (England: Elsevier Science) 2007; 73(10): 1657-1664.

2. Fourman GL, Millen MV. Pharma, Technol 1993; 17: 54.

3. Munson JW. Pharmaceutical analysis, part - B Marcel Dekar, Vol-II, New York; 1994. p. 87-135.

4. SOP Validation studies. Indian Pharma guidance academy Nagpure; 1996. p. 1-3.

5. Willar HHLL, Dean JA, Settle FA. Instrumental method analysis, $7^{\text {th }}$ ed, CBS publishers and distributions; New Delhi; 1986. p. 60-75.

6. Chowdary KPK, Himabindul G. Validation analytical method, Eastern Pharmacist; 1999. p. 39-41.

7. Snyder LR, Kirkland JJ. Practical HPLC Method development, Wiley inter science publications; New York; 1997. p. 685-712.

8. Indian Pharmacopoeia. Published by Indian Pharmacopoeia Commission-Ghaziabad; 2007. 1: 930-931.

9. Indian Pharmacopoeia. Published by Indian Pharmacopoeia Commission -Ghaziabad; 2007. 1: 1142-1143.
10. Maschera HJ, Zechb K, Maschera DG. Sensitive simultaneous determination of ciclesonide, ciclesonide-M1-metabolite and fluticasone propionate in human serum by HPLC-MS/MS with APPI. Journal of Chromatography B 2008; 869(1-2): 84-92. http://dx.doi.org/10.1016/ j.jchromb.2008.05.015 PMid:18514597

11. Dave HN, Makwana AG. Rapid Spectrophotometer methods for the determination of two novel steroids in bulk and pressurized metered dose preparations. International Journal of Pharmacy and Health Sciences 2010; 1(2): 68-76.

12. International Conferences on Harmonization, Draft revised Guidance on Validation of Analytical Procedure: Text and methodology. Q2A (R1). Federal Register, step 4 version; 2005.(www.ich.org/products/ guidelines/quality/article/quality- guidelines; 20/02/13)

13. Validation of compendial methods, General Chapter- 1225. United States Pharmacopeia XXIII, National Formulary, XVIII, Rockville, MD, The United States Pharmacopeial Convention, Inc; 1995. p. 1710-1612.

14. International Conference on Harmonization (ICH) of Technical Requirements for the Registration of Pharmaceuticals for Human Use, Validation of analytical procedures: Methodology, ICH-Q2B, Geneva; 1996. guidelines; 20/02/13)

15. V Ravichandran, S Shalini, KM Sundram, Rajak Harish. Validation of analytical methods - Strategies and Importance. Intern J Pharm and Pharma Sci 2010; 2(3): 18-22.

\section{Cite this article as:}

Momin Mohammad Abdul Motalib, Anisuzzaman Sharif Md., Begum Anjuman Ara, Bellah Sm Faysal, Islam Md. Mostaharul, Talukder Parimal. Development and validation of method for determination of Ciclesonide in (micronized) by HPLC. Int. Res. J. Pharm. 2013; 4(7):55-59 http://dx.doi.org/10.7897/2230-8407.04712 